\title{
Telangiectatic Glomangioma
}

National Cancer Institute

\section{Source}

National Cancer Institute. Telangiectatic Glomangioma. NCI Thesaurus. Code C5345.

A glomus tumor characterized by huge vascular channel formations. 